\title{
O PAPEL DAS REPRESENTAÇÕES SOCIAIS E DA EDUCAÇÃO PARA O DESENVOLVIMENTO DA IDENTIDADE DE GÊNERO
}

\author{
THE ROLE OF SOCIAL REPRESENTATIONS AND OF EDUCATION IN THE \\ DEVELOPMENT OF GENDER IDENTITY
}

Cléria M.L.B Bueno*

\begin{abstract}
Bueno CMLB. O papel das representações sociais e da educação para o desenvolvimento da identidade de gênero. Rev Bras Crescimento Desenvolv Hum 2006; 16(3):92-103.

Resumo: O artigo busca compreender de que forma se relacionam as identidades e as representações de gênero e como esta última, muitas vezes não reflete a verdadeira identidade individual do sujeito; embora seja uma construção socialmente reconhecida e aceita pela maioria dos indivíduos. Uma das implicações para essa situação refere-se à visão desigual baseada em diferentes níveis de socialização que atribuem a homens e mulheres padrões de condutas rígidos e que podem se cristalizar em condutas anti-sociais, geradoras de violências física e simbólica. $\mathrm{O}$ objetivo é criar um campo de discussão e atuação, tanto nas escolas, como na sociedade, levando até ambas a premissa da incorporação da perspectiva de gênero, assumindo-o como mais uma categoria não só de análise, mas também de distintas versões teóricas defendendo o direito à diversidade. A discussão amplia reconhecimento e a prevenção de atitudes e comportamentos que comprometem não somente o desenvolvimento emocional e psíquico do sujeito, assim como o de toda a coletividade.
\end{abstract}

Palavras-chave: Gêneros. Subjetividade. Identidade. Representação Social. Educação. Prevenção.

\section{Problemática}

O presente artigo tem por intuito compreender como o processo de socialização de meninas e meninos pode levá-los a viver em função dos papéis sexuais socialmente construídos e aceitos, em detrimento de aspectos pessoais e subjetivos que muitas vezes não se coadunam com aquilo que lhes são representados socialmente. O 'perigo' para o desenvolvimento emocional de meninos e meninas se dá quando há a exarcebação dos comportamentos e atitudes considerados pertinentes ao seu sexo, levando-os a viverem o extremo desta tipificação sexual, que é o estereótipo sexual.
Este poderá afetar a rotina e as tarefas mais simples destes sujeitos, uma vez que as possibilidades de flexibilização e desconstrução destes estereótipos levam um determinado tempo. Embora saibamos que tanto a tipificação como os estereótipos sexuais são frutos de suas épocas, cultura e meio social, havendo então a possibilidade de desconstrução do mesmo, este não se dá de forma imediata.

É preciso focar o papel da escola, da estrutura familiar e social imprescindíveis para se discutir e ampliar a discussão para atingirmos uma sociedade menos marcada pela segregação, pela desigualdade, pelo desconhecimento, intolerância e violência.

Departamento de Psicologia Universidade de Franca. Av. Dr. Armando Sales de Oliveira, 201- cep: 14.406.600- Franca, SP.E-mail: cleriabueno@terra.com.br ou cleria@unifran.br

Artigo baseado na Tese de Doutorado em Serviço Social: “Aves Raras” na profissão: a presença masculina na Psicolo gia e no Serviço Social. Franca (SP): Universidade Estadual Paulista "Júlio de Mesquita". Faculdade de História, Direito e Serviço Social; 2004. 
Inicialmente, proponho a diferenciação entre o termo e o conceito de gênero e, mais adiante, explico como a representação de gêneros tem a força de transformar homens e mulheres naquilo que de fato pressupõe, atuando assim, como uma 'profecia auto-cumprida', em detrimento da individualidade ou dos aspectos idiossincráticos de cada um. Podemos, então, imaginar a implicação das representações na identidade e na constituição psíquica do sujeito, que (re)age a estas representações e aos papéis préestabelecidos que lhes são designados e incutidos durante o processo de socialização.

Finalizando, proponho que as questões que versam sobre as perspectivas de gênero sejam discutidas nas escolas, na mídia, e na sociedade através de debates, e de ações públicas que garantam direitos e deveres iguais aos dois sexos. Ações que possibilitem às crianças, aos jovens e adultos conceber a perspectiva do outro, afastando-se de uma ótica que não seja somente a androcêntrica. A proposta é fornecer novos referenciais, para que tanto a alteridade como a diversidade, em seu termo mais abrangente, ofereçam novos referenciais ao desenvolvimento da identidade psíquica dos sujeitos, no intuito de coibir a violência que poderia ser evitada, se as pessoas pudessem contar com referenciais mais positivos de relacionamento entre os sexos, não mais calcados na anulação da individualidade de uns e no domínio de um sobre o outro.

\section{Gênero e conceito de gênero}

O termo gênero tem sido freqüentemente utilizado como sinônimo do conceito de gênero. Izquierdo $^{1}$, recorrendo ao dicionário, explica conceito como a representação mental de um objeto que manejamos com palavras; enquanto termo seria o uso da palavra, melhor utilizado pelo seu conteúdo do que por sua forma, e que nos remete ao significado do que representa. Termo é, portanto, "una unidad lingüística, mientras que concepto es la unidad de pensamiento" (p.21). A palavra usada para designar um conceito que, por sua vez, representa, constrói um objeto ou supõe a sua existência. Contudo, nem sempre a palavra coincide com o conceito que ela pretende traduzir, falseando, portanto, a verdade do objeto, que é a realidade última. Da palavra à conceituação pode haver um distanciamento da realidade do objeto, o que nos indica apenas o uso de uma convenção social, acabando por não ser fiel ao objeto em si:

La palabra es una representación del concepto que a su vez es una representación de la realidad. Ahora bien, tanto la palabra como el concepto son a su veces reales, por eso es doblemente importante tener presente que las palabras no coinciden necesariamente con los conceptos ni los conceptos con la realidad, que de hecho, la realidad es irreductible a conceptos (...) sendo posible usar una palabra que solo es una convención para designar algo, sin que necesariamente se produzca una coincidencia entre lo designado y el concepto que originariamente se representó con el término en cuestión, y eso es lo que ocurre respecto de los conceptos de sexo y género y respecto de las palabras que pueden ser igualmente utilizadas para referirnos a ellos ${ }^{1}$ (p.19-21).

Entre o conceito de um objeto e ele próprio existe, assim, uma intencionalidade que marca tanto o lugar do sujeito que enuncia como o do sujeito enunciado. Uma vez que nem sempre o conceito designa a realidade do objeto, mas subjuga-o a modelos que acabam por distanciálo daquilo que ele é na origem, usando da intencionalidade, podemos pensar nos discursos produzidos socialmente acerca das mulheres e também dos homens em um processo histórico e social, referindo-se a seus sexos corporificados e biológicos, como a unidade que deve representá-los enquanto gênero; enquanto sabemos ser este uma construção social, histórica e psíquica que não coincide necessariamente com o sexo que se tem. A afirmativa "la realidad es irreductible a conceptos" traduz nossa inquietude em se tomar um conceito, usando para isso a palavra, o discurso, para representar um sujeito individual ou coletivamente que não necessariamente se articula com a representação que se tem dele.

O ser humano como todo é muito maior e mais complexo do que as múltiplas representações sociais que o confinam a ser aquilo que de 
fato não é. O mais nefasto, no nosso ponto de vista, é a sentença de que 'uma mentira de tanto ser repetida pode se tornar verdade' - frase atribuída a Gobbells, ministro da propagando no governo de Adolf Hitler - , pois a representação social acaba tendo força na construção da identidade dos sujeitos.

Neste encadeamento, tomar-se um pelo outro seria equivalente a dizer que "mulher $=$ inferior", pois este conceito - o de inferioridade moral e intelectual, foi construído a partir da observação de sua inferioridade física em relação à força muscular do homem, e por continuidade, toda a extensão de sua existência também o deveria ser. Esta conexão entre inferioridade e a mulher, ou tudo que se referisse ao gênero feminino, prevaleceu durante séculos no discurso misógino, como pode ser exemplificado pelo momento histórico em que se discutia ter a mulher ou não uma alma.

Esta naturalização e banalização da ligação estabelecida foi, e continua a ser, em outra medida, a responsável por inúmeras injustiças e violências- concretas ou simbólicas- cometidas contra as mulheres como, por exemplo, a proibição a determinados trabalhos com o pretexto de salvaguardar ou sua saúde, ou garantir sua posição de 'defensora do lar'. Na verdade, estas soluções simplistas escondem em sua atitude paternalista uma manobra para deslocá-las do mercado de trabalho, tornando-as menos competitivas.

\section{Feminino: o 'gênero' dos gêneros}

A explicação mais óbvia para que gênero seja tomado como sinônimo de gênero feminino vem do próprio movimento feminista, que, sobretudo na segunda metade do século XX, conseguiu atrair os olhares de todo o mundo para a situação de vida e de trabalho das mulheres.

Antes mesmo de falarmos em movimento feminista, movimento este que se intensifica na década de 60 do século XX, trazendo denúncias contra a exploração das condições do trabalho exercido por mulheres, criando-se teorias quanto ao controle sobre o corpo e a sexualidade feminina, sobre a violência cometida contra as mulheres, sobre as condições de vida, de estudo e profissionalização das mulheres; sobre a participação destas na política, entre outros assuntos; é preciso entender que em épocas distintas e remotas houve mulheres que se fizeram ouvir em suas reivindicações.

Embora fuja ao intuito deste artigo um histórico do próprio movimento feminista em si mesmo, vale a pena ressaltar a atuação de algumas mulheres, ao longo da história da humanidade, como Olympe de Gouges ${ }^{2}$, que ainda em 1759 escreve a "Declaração dos direitos da mulher e da cidadã", em resposta ao movimento do Iluminismo francês, que pregava a igualdade, liberdade e fraternidade entre os homens apenas, relegando à mulher uma condição de cidadã de segunda classe, pois os mesmos princípios libertários e democráticos não as alcançavam.

Em 1790, a inglesa Mary Woolstonecraft ${ }^{3}$ escreve "Reivindicação dos direitos da mulher" num claro posicionamento político defendendo o direito das mulheres participarem dos mesmos principios de liberdade, autonomia e cidadania, há exatos 216 anos, liberdade que lhe fora subtraída á guilhotina, por ser considerada uma subversiva ao sistema.

Citando algumas pioneiras feministas brasileiras, em 1832 Nísia Floresta publica "Direito dos Homens injustiça para as mulheres", baseada em "Reivindicação dos direitos da mulher"de Woolstonecraft, de 1792, da qual foi a tradutora para o português, além de outras tantas mulheres que lutaram primeiramente pelo direito ao voto e depois para serem eleitas, ou porque denunciaram as injustiças a que estavam submetidas as mulheres de sua época ${ }^{4}$.

São muitos nomes e exemplos de mulheres que, a seu modo, manifestaram-se, organizando debates, escrevendo, enfrentando o poder estabelecido, a norma e o as convenções sociais de suas épocas.

Mas o movimento feminista tal como o concebemos - como um movimento social de um determinado segmento da sociedade -, surgiu de forma organizada em meados do século $\mathrm{XX}$, e intensificou-se a partir da publicação da "Mística feminina", em 1963, de Betty Friedan ${ }^{5}$ e de "O segundo sexo", em1949, de Simone de 
Beauvoir ${ }^{6}$.

Foi preciso que o movimento feminista chamasse a atenção para o fato de que "o espaço privado é também um espaço político”, como comenta Haicault ${ }^{7}$, porque ele reproduz valores sociais e históricos, tanto economicamente falando, como no campo do discurso;

[tradução nossa] "Compreende-se, nestas condições, porque a retomada da questão do corte entre espaço privado/ público, coincidindo com a separação mercado/ não mercado do discurso econômico moderno, estiveram, desde os setenta, no centro do debate feminista científico e, sob outra forma, do movimento militante. Afirmando que o espaço privado é político, que a produção doméstica é socialmente útil e participa, de uma certa maneira, mesmo que indiretamente, da produção do valor, portanto, na economia geral das sociedades contemporâneas, as mulheres redefiniram o espaço privado de uma visão naturalista para uma visão social e histórica". ${ }^{7}$ (p.32). ${ }^{* *}$

Desta forma, entendemos que o "feminismo define uma perspectiva, não um sexo", 8 (p.45), pois compreende uma discussão que ultrapassa questões ligadas às condições do sexo feminino, focalizando-o sob a ótica dos direitos, da cidadania, da dimensão política e social onde se encontram os sujeitos.

Há, como em todo movimento, teoria e discurso, posições diferentes entre si ou até mesmo antagônicas, discussão que foge ao interesse desta análise, mas é digno de se citar que, embora diferindo ideologicamente entre si, o fato é que as diferentes formas de manifestação feministas têm em si a marca do repúdio ao modelo androcêntrico de construir e conceber as ciências, o conhecimento e as artes em geral, modelo este que enfoca e faz prevalecer, no cerne da discussão, o ponto de vista unicamente dos homens, ou seja, a ótica masculina.

Até mesmo a própria psicanálise, que contribuiu para a compreensão da sexualidade, propondo um desenvolvimento da psicossexualidade, foi alvo de críticas. Isto porque ela representa e reproduz a moral vitoriana de sua época, tomando como modelo de normalidade e de moralidade, o sexo masculino, e não o feminino.

No Brasil, o movimento feminista seguiu linhas distintas desde o seu nascimento, e foi impulsionado após 1975, ano em que a ONU decretou o Ano Internacional da Mulher. Muitos temas foram propostos concernentes ao trabalho, aos direitos civis, à violência, à sexualidade das mulheres.

Os alvos privilegiados da crítica são o Estado, o aparelho escolar, as empresas. A família, em si, não ocupava lugar central nas preocupações das feministas. No entanto, indiretamente, a organização familiar era objeto de questionamento, quando se denunciavam a violência no interior da família e o trabalho doméstico, a dupla moral sexual, a educação desigual de homens e de mulheres. ${ }^{9}$ (p.110).

Por terem deflagrado séculos de dominação e submissão e terem proclamado sua 'autoliberdade', o movimento feminista, como mencionado anteriormente, é um movimento de mulheres, feito pelas mulheres; portanto, os estudos de gênero passaram a ser encarados, primeiramente, como estudos sobre mulheres, feito pelas mulheres para um público constituído de mulheres. Neste sentido, toma-se erroneamente o termo gênero, quer seja isoladamente, quer seja em 'relações de gênero', embora este último nos pareça óbvio que implica o outro gênero -, como 'coisa de mulher'.

Uma 'mulher' é um sujeito específico; gênero denota uma relação de poder entre os sexos e refere-se tanto a homens quanto às mulheres; 'fêmea 'designa sexo biológico; 'feminino' refere-se a maneirismos e comportamentos idealizados das mulheres num lugar e época es-

\footnotetext{
On comprend dans ces conditions pourquoi la remise em question de la coupure privé/ publique, coïncidant ave la séparation marchand/ non marchand du discours économique moderne, a été, dès les annés soixante-diz, au centre du débat féministe scientifique et sous une autre forme, du mouvement militant. En affirmant que le privé est politique, que la production domestique est socialment, utile et participe d'une certaine maniére, même indirectement, à la production de la valeur, donc à l'economie générale des sociétés contemporaines, les femmes ont fait passer l'espace privé d'une vision naturaliste à une vision sociale et historique
} 
pecíficos que podem também ser adotados por homens; e 'feminista' defende uma posição de agenda política. ${ }^{8}$ (p. 32).

Por terem sido, historicamente falando, as primeiras a pensarem sua condição em relação ao outro sexo, e terem inicialmente denunciado esta condição, o termo gênero ficou como se fosse 'coisa de mulher'. "Nas pesquisas, normalmente, o uso do conceito gênero tem substituido a palavra mulher, mas é igualmente utilizado para sugerir que a informação a respeito das mulheres é necessariamente informação sobre os homens" ${ }^{10}(\mathrm{p} .69)$.

\section{$O$ 'outro' gênero: o masculino em perspectiva}

É a partir de 1970, mais precisamente na segunda metade, que se começou a falar com mais visibilidade do gênero masculino, da identidade masculina, e do próprio masculino em si, como o outro gênero. É assim que o termo gênero vem resgatando, aos poucos, sua devida conotação: de um conceito que inicialmente serviu para distinguir sexo, em seu sentido biológico-anatômico, de identidade, no sentido de uma construção social e psíquica.

Esta pretensa 'invisibilidade' do gênero masculino é o que contribuiu por associá-lo ao humano em si mesmo, conferindo-lhe um caráter de universalidade, pois ao tratarmos os homens como se não tivessem gênero, universaliza-se a tudo o que se refere e relaciona-se ao humano em si.

À medida que o sujeito desaparece, ele nega tudo que não é da mesma espécie que ele; (...) modo puro [do] princípio masculino da dominação. Ao fazer de todos, sem exceção, inclusive os pretensos sujeitos, seus objetos, este último, converte-se em passividade, virtualmente o que é feminino ${ }^{11}$ (p. 39).

Badinter ${ }^{12}$ em seu livro $X Y$ - sobre a identidade masculina, cita um fato ocorrido com Michael Kimmel, autor da premissa da 'invisibilidade' do gênero masculino:

O autor desta proposição relata o dia em que tomou consciência disso ao assistir a uma discussão entre uma mulher branca e uma mulher negra sobre a questão de saber se a seme- lhança sexual superava as diferenças raciais. A branca afirmava que o fato de serem ambas mulheres tornava-as solidárias, acima da diferença de cor. Mas a negra não concordava.

- 'Quando você se olha pela manhã no espelho, o que vê?

- Vejo uma mulher -respondeu a branca.

- É exatamente este o problema -replicou a mulher negra. - Eu vejo uma negra. Para mim a raça é visível a cada dia, porque ela é a causa do meu handicap nesta sociedade. A raça é invisível para você, motivo pelo qual a nossa aliança sempre me parecerá um pouco artificial.'

Kimmel compreendeu que, ao se olhar no espelho de manhã, ele via 'um ser humano, universalmente generalizável. A 'pessoa genérica' o que estava dissimulado -a saber, o que ele tinha um gênero e uma raça -tornava-se invisível de modo espantoso. A explicação sociológica para tal cegueira está, diz Kimmel, no fato de que nossos privilégios são com freqüência invisíveis para nós ${ }^{12}$ (p.10).

Gênero, em verdade, trata de algo mais subjetivo, como o sentimento de uma identidade sexual, implícito numa ordem objetiva que é a realidade das diferenças entre os corpos. Esta diferença serviu de pretexto para demarcar o lugar desses corpos -, simbólica e concretamente nas relações sociais. Falar em gênero é sempre um conceito relacional, dialético, não sendo possível conceber um sem o outro; portanto a masculinidade atribuída ao homem é um conceito que depende da feminilidade:

[tradução nossa] "a masculinidade está longe de ser considerada uniforme. É vista não como a 'essência do homem', mas antes como um produto de forças históricas e culturais, que assumem muitas dimensões (...). Confirmando que a masculinidade não deve ser tomada como um dado mas como uma variável" ${ }^{13}$ (p.208/ $222)^{* * * *}$.

Ora, se a construção dos gêneros são codependentes, é de se supor que qualquer transformação em um altera o outro. O empírico comprova exatamente isto; falar em homens, ou ainda em masculinidades, só foi possível a partir do movimento feminista e das mudanças ideológicas e comportamentais que este trouxe às mu- 
lheres -e homens - das gerações posteriores, desestabilizando, portanto, a norma, o genérico, a pretensa universalidade masculina.

A história das sociedades patriarcais prova que são sempre as mulheres, e não os homens, que suscitam os grandes questionamentos. (...) ao contrário do que diz a ideologia do patriarcado, os homens não são os primeiros referenciais da humanidade, e sim as mulheres. É em relação a elas e contra elas que eles se definem $^{12}$ (p.11).

Atualmente os estudos de gênero têm a preocupação de compreender e discutir as desigualdades dos sujeitos no âmbito das interações de poder que se perpetuam e atravessam as construções da feminilidade e da masculinidade através do discurso, das instituições, dos códigos, das práticas e dos símbolos e das hierarquias entre os gêneros. É lícito afirmar que, hoje, fala-se de identidades e de como estas são representadas em sua multiplicidade de fatores que a compõem (classe, etnia, raça, nacionalidade).

Desta forma, o termo gênero é compreendido em função dos aspectos sociais, culturais e históricos pelos quais as diferenças sexuais são representadas, impostas e, de certa forma, aceitas pelas mulheres e homens. "Gênero é um conceito relacional, ou seja, que vê um em relação ao outro e considera que estas relações são de poder e de hierarquia dos homens sobre as mulheres" ${ }^{14}$ (p.30).

Na verdade, o que está em jogo, é a questão de quem é o ser diferente, implicando aí, de fato, o jogo das desigualdades. Neste sentido, vale ressaltar que a diferença entre homens e mulheres não pode ser o álibi para a exclusão e a desigualdade. Os Estudos de Gênero "são campos de estudos marcadamente engajados, dirigidos não apenas para a análise, mas para a intervenção social" ${ }^{15}(\mathrm{p} .157)$, na compreensão de como estas diferenças são construídas e socialmente valorizadas ou negadas.

Mas falar de masculino e feminino é tam- bém remeter à idéia da construção destas duas identidades, e dos papéis sociais que para cada um dos dois gêneros cabem. Os conceitos de construção de identidade e de representação de papéis sociais estão, a nosso ver, atrelados e são indissolúveis, visto que muito da representatividade dos papéis sociais, e mesmo da construção da masculinidade e feminilidade se pautam por atitudes e comportamentos a priori esperados e validados pela ação social.

\section{Identidade de gênero e representação de papéis sociais}

Por que se fala em construção de identidade (de gênero) e logo em seguida de representação de papéis? Falar da identidade não traz implícita a representação que esta deve ter perante o meio social?

Identidade é uma palavra de origem latina que significa 'igual $a$ '. Por sua etimologia podemos então pensar, que a construção da identidade humana e, sobretudo da identidade de gênero, passa pela situação de ser 'igual a' algo já anteriormente desenvolvido ou em última análise, já existente.

É interessante notar que identidade é o que confere individualidade ao sujeito. Dizemos que cada um, apesar de toda influência cultural e social que recebe, é único em sua individualidade, em sua identidade. Nem mesmo sua impressão digital - a marca que carregamos em nossa carteira de identidade - se repete em outro ser humano.

Somos únicos em nossa identidade, mas estranhamente marcados pela identidade do outro que nos forma, que nos rodeia ou que investe afetivamente em nós mesmos. Construir uma identidade é, então, paradoxalmente, deixar morrer um pouco das velhas 'cascas', projetos e identidades alheias, sobrepostas ao nosso eu original, para que aquilo que deve ser idiossincrático, próprio do sujeito, emirja. É deixar o 'igual a' conceito que permeia o significado de identida-

\footnotetext{
masculinity has been found to be far from uniform. It is seen not as 'the essence of man', but rather as a product of cultural and historical forces, which assumes many dimensions (...). Confirm that 'masculinity' should not be taken as a given but as a variable.
} 
de, para se 'tornar semelhante a', no nosso caso, semelhantes a outros seres humanos.

Identidade compreendida como metamorfose constituída no bojo de um contínuo processo de transformação. Esse processo pode até se referenciar ao individual ou ao coletivo - grupos, organizações, instituições, culturas -, e ocorre num determinado tempo (história) e espaço (geografia). A identidade é sempre histórica e dialética, construída a partir da composição ou oposição de elementos complexos que se mantêm, ou se modificam no fluxo do tempo. ${ }^{16}$ (p.58).

A identidade depende da trama das relações sociais e familiares nas quais estão inseridos todos os humanos. Identidade é, então, o que confere o caráter próprio, idiossincrático de um sujeito. É o que o representa, o que o revela, embora não sejamos iguais aos outros, o que tornaria o conceito de identidade sinônimo de igualdade -, somos sim, paradoxalmente, em nossas diferenças individuais, semelhantes aos outros.

A construção da identidade passa, portanto, pela forma como somos aceitos, desejados, esperados e integrados no seio familiar, e também pelos reforços que recebemos ao longo de nossas vidas; reforços positivos ou negativos-, nas inúmeras tentativas que fazemos, ainda crianças, de buscar autonomia para esta identidade nascente. É o que explica a natureza tímida e apegada de uns, e o senso de autonomia e liberdade para outros. Uns foram encorajados a serem o que são, a buscarem suas próprias respostas, enquanto outros foram por vezes punidos ou tidos como um 'mau menino' 'uma menina desobediente', quando se distanciavam dos padrões moralmente aceitos por sua família e/ ou meio social.

Já o conceito de semelhança confere o caráter que nos torna semelhantes, parecidos, de mesma origem ou aparência que o outro, contudo ressalva nossa verdadeira individualidade e unicidade.

O conceito de identidade se articula ainda com o de personalidade, que é o conjunto de características de ser que definem uma pessoa, buscando sempre a adaptação do sujeito ao meio em que ele vive. Por isto dizemos que ela é única, embora marcada pela atuação do outro, des- de o início da vida.

Com a identidade de gênero não é diferente: aprendemos desde cedo o que é próprio para cada um dos dois gêneros existentes, desde atitudes, a brincadeiras, modo de falar, de agir, de se vestir, etc.

A identidade de gênero denota como um homem ou mulher individual apropria aspectos de ideologias de gêneros como parte de seu senso de eu. As identidades dos indivíduos podem mudar de acordo com o contexto, ambiente e época (...), a atribuição de gênero refere comportamentos esperados de um individuo em virtude dele ser homem ou mulher. ${ }^{8}$ (p.46)

Como se articulam identidade de gênero e representações de papéis? Se a identidade, assim como a identidade de gênero, é representada socialmente, seriam os sujeitos somente atores sociais, desenvolvendo apenas papéis prédeterminados?

Não é a opinião de Louro $^{15}$, que entende que o gênero, ao fazer parte do sujeito aliado aos outros aspectos de sua identidade (classe, etnia, raça, nacionalidade), faz parte do sujeito, e não apenas se apresenta como regra, padrões ou formas arbitrárias que os sujeitos têm de assumir socialmente, como os papéis.

A vivência acaba por conferir uma qualidade ou status ao sujeito ou ao grupo social, e que o representa diante dos seus pares. Por exemplo, a fome, a magreza, a expressão de desalento e dor que vemos nos olhos e nas faces dos povos miseráveis do terceiro mundo, representam-nos enquanto seres sociais. A condição da miséria os caracteriza - pela fome e pela desesperança -, como sujeitos. É a fome que os representa diante de outros povos, e não sua humanidade. "A representação contínua se torna disponível como saber, especialmente como signos e sistemas de signos para utilização atual” ${ }^{17}$ (p.829).

\section{Representação social e seu impacto na construção da identidade de gênero}

Se a representação é algo posto como fato sabido, disponível ao saber, quem o construiu, e para que? Em que medida este "conhecimento 
tornado disponível como saber' é apenas um dado fiel, um relato ou retrato da maioria, ou é um constructo mental definido por outros?

Do ponto de vista sociológico, também é possível entender as representações sociais como a forma pela qual os sujeitos se vêem e se representam socialmente, como preconizou Durkheim, sendo "a maneira como o grupo se pensa em suas relações com os objetos que o afetam" (apud ${ }^{18}$ p.156).

Para Durkheim (apud ${ }^{18}$ p.157), a representação social não é, do ponto de vista individual, consciente:

Algumas representações, mais do que outras, no pensamento do autor, podem exercer sobre as pessoas uma espécie de coerção para atuar em certo sentido. Ainda para si, não existem representações falsas, todas têm um sentido de ser e respondem de forma diversificada a condições dadas da existência humana. ${ }^{18}$ (p.157).

Se for fato de que "não existem representações falsas, todas têm um sentido de ser e respondem de forma diversificada a condições dadas da existência humana”, seriam mesmo as mulheres inferiores? Seriam também os homens necessariamente combativos, pouco emocionais, moral e intelectualmente superiores às mulheres? Anacronicamente, a visão de que um homem nunca podia ser visto combalido ou hesitante foi responsável não somente pelo massacre psicológico, emocional e espiritual de mulheres, como também de homens.

Identificar-se somente e tão somente com a representação social que o seu sexo tem é alienar-se de si mesmo, e de todas as potencialidades realizadoras que ambos os sexos têm.

Então, o que teria surgido primeiro: as representações sociais que forjaram uma identidade de gênero, ou as identidades que refletiram as representações que se tem de ambos? Uma ambivalência falaciosa pode nos levar a defender o ponto de vista da 'culpabilidade da vítima', esquecendo do peso da tradição, da cultura, da educação e da socialização, que levam mulheres e homens a adotarem os comportamentos que os estereotipam e os representam socialmente, não porque de fato sejam aquilo, mas porque assimilaram esses valores. "A relação ambivalente com a identidade coletiva, contudo, não é problema exclusivo das mulheres, mas comum aos grupos minoritários inferiorizados ${ }^{19}$ (p.241).

Essa relação antagônica entre os sexos assenta-se nos valores patriarcais que conferem ao homem o status e o poder de decisão e a naturalização de todos os sistemas - políticos, religiosos, científicos, ideológicos -, que refletem a visão androcêntrica para a humanidade em geral. Estes valores se iniciam na família, com o homem dominando o espaço da produção, e a mulher no ‘domínio' da reprodução; mas não se limitam exclusivamente a ela.

Isso remete à questão das classes sociais, que confere a quem produz o poder, restando a quem reproduz o lugar da subordinação. Este é historicamente o lugar da mulher e de todos os demais segmentos minoritários da humanidade enquanto lhes faltar representatividade que lhes confira poder e prestigio social e político;

(...) é evidente que nenhuma prática social concreta não é jamais a pura expressão ou manifestação de uma relação social única. Partir, mais uma vez, das relações sociais é, de início, romper com os pontos de vista unilaterais, a partir dos quais a família é apenas um instrumento do capital e, como tal, patrulhada pelos aparelhos estatais, e por elas incessantemente reproduzida (...), a partir das relações sociais entre os sexos e de classes (...) sem negligenciar, no entanto, a permanência da estrutura e seu peso sobre as práticas sociais. ${ }^{20}$ (p. 34).

Devido a isso diz-se que o feminismo não é algo 'de mulheres', mas uma tomada de consciência política que busca a emancipação de todos que se vêm representados nestes segmentos. Se a representação social de um gênero é uma construção coletiva, então não se sustenta quando confrontada com a identidade, que é aquilo que é próprio, idiossincrático de cada sujeito.

A representação, assim, não é ipso facto a representante da identidade do sujeito, pelo menos não da identidade a nível pessoal, mas talvez algo de uma identidade construída coletivamente no jogo de atribuições e conveniências que a trama social tece para ambos os sexos.

A identidade de gênero nos liberta de 
sermos atores sociais - aqueles que representam um determinado papel - , porque a identidade é algo constitutivo de nossas existências, de nossa personalidade, e, portanto, não é, a identidade, um lugar do outro, mas de nós mesmos. Todavia, a identidade não está só; ela articula-se com a representação social que nos (re)presenta publicamente como somos imaginados. Embora ela seja inerente a cada sujeito, a identidade individual não é socialmente reconhecida, mas coletivamente representada pelo seu sexo, gênero, raça, ideologia, orientação sexual, que têm estes sujeitos.

Paradoxalmente, ao falarmos em representações somos realmente atores sociais, pois o papel desempenhado pelos atores sociais os representa -'apresenta-se em lugar de alguém'mesmo que seja este outro representado a imagem de si mesmo, por vezes distorcida no jogo das representações sociais, e que acaba por confiscar-lhe aquilo que lhe é próprio, verdadeiro, inerente e indivisível: sua identidade.

Vivemos, pois, sob o manto de uma contradição: pela ótica da identidade, somos agentes únicos de nossas vidas, somos sujeitos de nossa história; mas pelo peso da representação social, que se atrela aos valores de uma determinada época e aos interesses da classe e do sexo hegemônico, somos atores, pois desenvolvemos papéis que são construídos fora de nossas identidades, e os representamos como se fossem nossas aspirações, convicções e crenças pessoais. Tornamos o exterior, o construído como se fosse algo vivenciado, idiossincrático, sem perceber as implicações para nossa identidade de valores que sequer repudiamos.

Nesta direção, Bourdieu ${ }^{21}$ aponta a força da representação como algo imposto, via discurso, sendo que a ideologia social, incorporada como verdade, é transmitida na sociedade e na escola.

O poder sobre o grupo a que se pretende dar existência enquanto grupo é, ao mesmo tempo, um poder de fazer o grupo impondo-lhe princípios de visão e divisão comuns, e portanto, uma visão única de sua identidade e visão idêntica de sua unidade. ${ }^{21}$ (p. 111).

É no discurso hegemônico, portanto, que o poder se institui, e este poder está necessaria- mente atrelado ao discurso objetivo que engloba, em sua prática, as subjetividades tramadas na fala, subjetividades estas que indicam o lugar de poder e não poder de cada indivíduo:

(...) não se deve esquecer que as trocas lingüísticas - relações de comunicação por excelência - são também relações de poder simbólico onde se atualizam as relações de força, entre os locutores e os seus respectivos grupos. ${ }^{21}$ (p.23-24).

O processo de socialização de meninos e meninas, cristalizado em determinados papéis, demora a conseguir mudar antigos padrões comportamentais, arraigados devido a uma educação repressora e segregacionista:

As representações, em essência, são produtos da posição que os sujeitos sociais ocupam na estrutura e tem a função de emprestar significado à realidade. ${ }^{18}$ (p.205).

De maneira simplista, costuma-se considerar que os homens ganharam, pela imposição física e poder, a batalha 'contra' as mulheres; mas visto de mais perto se tornaram tão alienados de si mesmos, de seus corpos físicos e sentimentos, que precisaram inventar o "mito do eterno guerreiro', sempre em combate, sempre distante emocionalmente de si mesmo e do sexo oposto, para sustentarem a fantasia de não ser perdedores. Esta seria, parodiando Beauvoir a 'Mística do Macho'; a de que tudo podem e conseguem, mesmo que não devam.

O preço? As guerras entre povos, as batalhas do próprio cotidiano para sustentarem a máscara do super-herói, as doenças emocionais que os deixam vulneráveis a si mesmos, as doenças físicas que dilaceram seus corpos físicos, o distanciamento emocional do sexo feminino que os condenam a ver-se como inimigos e opositores, numa relação nunca, ou quase nunca, dialética. Estes são apenas alguns pontos mais evidentes que resultam da insistente e teimosa posição que o homem (ou a maioria deles) assume na 'mística masculina', correspondendo ao perfil de um 'homem de verdade', sempre disposto ao domínio e, paradoxalmente, à alienação, pois afastam de si mesmos o campo da intimidade:

Quando está sendo socializado, um menino aprende que não deve incluir como parte de seu 
crescimento o desenvolvimento de recursos para construção de vínculos afetivos duradouros capazes de suportar a transferência necessária a uma relação de intimidade. Dentro desta perspectiva, as relações interpessoais masculinas se restringem a encontros sociais em que pouco se fala ou se compartilha de experiências vividas; elas são mencionadas por atitudes em que o que está em questão são demonstrações de atitudes de 'macho', os ditos 'homens de verdade' ${ }^{22}$ (p. 18).

Essa autora nos aponta ainda que a uma transformação da intimidade seria, uma das possibilidades que se abrem diante dessa crise diz respeito à transformação da intimidade. (...). Para um homem, a noção de intimidade não pertence a seu processo de socialização, não é algo que ele vá aprender, exercitar, desenvolver. Portanto, o modelo de masculinidade a ser seguido pelos meninos é o deste 'homem de verdade'. Ele é solitário e reservado quanto a suas experiências pessoais, ou então superficial e prático, orientado para agir e realizar atividades. ${ }^{22}$ (p.20-21).

Anthony Giddens ${ }^{23}$ em seu livro A transformação da intimidade também compreende a necessidade desta transformação em benefício de uma sociedade mais igualitária e justa. Para tanto, a socialização dos meninos teria que ser revista e posta em outros termos, que não mais o da exclusão, expropriação e domínio sobre o sexo feminino. A experiência da sexualidade é, no entender de Giddens ${ }^{23}$, um espaço de "luta política, além também de ser um meio de emancipação" (p.199) sendo ainda "um ponto de transformação especialmente dentro das relações de poder” (p.28).

Se 'o preço da liberdade é a eterna vigilância', como está escrito na sabedoria popular, a eterna vigilância também dá o seu preço: não relaxar nunca, estando sempre de 'espada em punho'. Talvez não seja à toa que o órgão sexual masculino, sempre disposto a ferir, a penetrar, a ocupar, seja comparado à espada que fere, que mutila e retalha, ou ainda a outros apelidos que revelam sempre sua natureza fálica: cortante, perfurante, penetrante, invasora.

O papel masculino que uma sociedade sexista impõe ao homem é uma imagem de machismo e de virilidade muitas vezes tão mutila- dora para o homem como a imagem da feminilidade é para a mulher. Por isso, a possibilidade de um movimento de libertação dos homens ligase a uma tomada de consciência, por parte destes, das limitações que lhes são impostas pela sua própria sociedade sexista. (Tolson 1977, p.11 apud $^{22}$ p. 19).

\section{CONSIDERAÇÕES FINAIS}

Tanto o estereótipo do guerreiro, quanto o da donzela frágil, limitam homens e mulheres a acreditar que, mais do que cumprir a meta de uma simples representação social de seus sexos, deveriam seguir sua identidade pessoal, sua personalidade, tomando-se literalmente o sentido da palavra 'pessoa': a realização de sua meta de vida.

Esta mudança de paradigma tem seus alicerces diretamente ligados ao papel que a educação oficial, e não oficial, tem diante desta tarefa: o de permitir emergir uma nova consciência que aceite as diferenças como um princípio e um direito à diversidade, e não mais como uma prerrogativa para as desigualdades.

Concordo com Louro ${ }^{15}$ quando defende a necessidade de se estudar o gênero pois, mais do que um marco teórico, é um campo de intervenção social, e esta deveria ser a preocupação de todos interessados em garantir a qualidade de vida das gerações futuras. A necessidade de se criar condições para o debate e ações, desde uma perspectiva de gênero, tem suma importância tanto no aspecto social e educacional quanto na área de saúde, pois somente a compreensão das vicissitudes de cada sexo, e de suas diferenças, irá erradicar a violência cometida contra as mulheres e outras minorias, geradas pelo desconhecimento e pela desconfiança entre os sexos.

O conhecimento do verdadeiro sentido de alteridade e da diversidade poderá contribuir para um entorno social mais tolerante, menos violento e mais aberto a aceitar o outro de fato como ele é, seja esta pessoa homem ou mulher, negro ou branco.

$\mathrm{O}$ diferente da norma não constitui uma ameaça à integridade emocional e psíquica, pois 
a aceitação e a abertura para o outro acontecem de maneira dialética: permitindo que ambos os lados se apresentem e se reconheçam, não tendo mais que ficar justificando valores e posições pré-concebidas, armadas e fundamentadas em constructos sociais que negam a dimensão psíquica e unitária deste sujeito, e não apenas reservando a ele o espaço do convencional, mesmo que este espaço em nada sirva para a construção de sua singularidade.

A função social do educador, e de todos os que lidam de maneira direta ou indireta com o público, seja através dos sistemas de saúde, da educação, jurídico e social, é manter a possibilidade de que a multiplicidade de existências e experiências humanas sejam aceitas em sua totalidade e compreendidas como mais um cami- nho possível de ser percorrido. É deste modo que o gênero deverá ser compreendido em sua importância política e social: como uma categoria de análise que leva em consideração toda a ação humana.

$\mathrm{O}$ direito à alteridade e à diversidade passa pela reconceituação de nossos trabalhos, e pela necessidade de olhar para estes diferenciais com a riqueza e o colorido que estes aportam, não mais 'homogeneizando' o tratamento a ser dispensado a cada pessoa ou 'usuário' desses sistemas citados, mas, ao contrário, levando em consideração suas diversidades culturais, históricas, sociais, de classe, etnia, crença e gêneros.

O diferente somos todos nós, depende apenas do lado de quem vê. E queremos viver esta diferença.

\begin{abstract}
This article is an adaptation of the doctoral dissertation submitted to the Post- Graduation Program in Social Work at UNESP (São Paulo's State University). In this article I try to understand in what way identities and gender representations are connected, taking into account that in many ways the true individual identity is not reflected in the latter, although it is a socially recognized construction accepted by the majority of individuals. One of the implications of this situation concerns the unequal view based on different social levels that attribute to men and women strict conducts that may be crystallized in anti-social attitudes, producing some disorders such as physical and symbolical violence. The objective is to create the possibility of discussing that and acting not only in schools but also in social environments, taking the gender prospect to them, recognizing it as one more category of analysis with different theoretical versions, and defending the right to diversity. The discussion broadens the recognition and prevention of attitudes and behaviors that can cause some disorders that delay the individual's emotional and psychical development, thus affecting all the collectivity in which he/she lives.
\end{abstract}

Key words: Genders. Subjectivity. Identity. Social Representation. Education. Prevention.

\section{REFERÊECIAS}

1. Izquierdo MJ. El malestar en la desigualdad. Madrid: Cátedra; 1998.

2. Gouges O. Declaração dos direitos das mulheres e da cidadã [texto na Internet]. 1791 [acesso em 15 set 2006]. Disponível em: http:// www.pgr.mpf.gov.br/pgr/pfdc/ legislacao_biblioteca/pdf.

3. Woolstonecraft MA. Vindication of the rights of men [texto na Internet]. 1790 [acesso em 26 out 2006]. Disponível em: http:// www.dominiopublico.gov.br/download/texto/ $\underline{0532 \text { Bk.pdf }}$
4. Pinto CRJ. Uma história do feminismo no Brasil São Paulo: Fundação Perseu Abramo; 2003.

5. Friedan B. A mística feminina. Petrópolis: Vozes; 1971.

6. Beauvoir S. O segundo sexo. Rio de Janeiro: Nova Fronteira; 1982.

7. Haicault M. Femmes et hommes entre espaces publics et espaces privés. In: Mattoso K, Santos I, Rolland D. Les femmes dans la ville: un dialogue franco-brésilien. Paris: Université de Paris-Sorbonne; 1997. p. 29-48.

8. Schienbinger L. O feminismo mudou a ciência? Bauru: Edusc; 2001.

9. Romanelli G. Famílias de camadas médias: trajetória da modernidade [tese]. São Paulo: 
Faculdade de Filosofia, Letras e Ciências Humanas da Universidade de São Paulo; 1986.

10. Oliveira EM. A mulher, a sexualidade e o trabalho. São Paulo: Hucitec/CUT; 1999.

11. Adorno T. Mínima moralia: reflexões a partir da vida danificada. 2a ed. São Paulo: Ática; 1993.

12. Badinter E. XY sobre a identidade masculina. Rio de Janeiro: Nova Fronteira; 1993.

13. Cross S, Bagilhole B. Girls' jobs for the boys?: men, masculinity and non-traditional occupations. Gend Work Organ. 2002;9(2):20426.

14. Faria N, Nobre OM. Gênero e desigualdade. São Paulo: Sempreviva Organização Feminista; 1997.

15. Louro GL. Gênero, sexualidade e educação: uma perspectiva pós-estruturalista. $4^{\mathrm{a}}$ ed. Petrópolis: Vozes; 1997.

16. Antunes MAM, Strazzieri C, Soares LFM, Moreira MM, Lopes MMA, Baptista MTDS. Jeca Tatu e a identidade do povo brasileiro: contribuição aos estudos sobre as relações entre psicologia e história. In: Jacó-Vilela AM, Cerezzo AC, Rodrigues HBC, organizadores. Clio-psyché ontem: fazeres e dizeres psi na história do Brasil. Rio de Janeiro: Relume Dumará/FAPERJ; 2001. p. 57-82.
17. Dorsch F, Hacker H, Stapf KH, editors. Dicionário de psicologia Dorsch. Petrópolis: Vozes; 2001.

18. Osterne MSF. Família, pobreza e gênero: o lugar da dominação masculina. Fortaleza: Eduece; 2001.

19. Galiatti A. Cidadania e diferença de gênero: o problema da dupla lealdade. In: Bonachi G, Groppi A, organizadores. O dilema da cidadania: direitos e deveres das mulheres. São Paulo: Edunesp; 1995. p. 231-59.

20. Haicault M, Combes D. Produção e reprodução: relações sociais de sexos e de classes. In: Kartchevsky-Buport André KartchevskyBulport, Danièle Combes, Monique Haicault, Helène Le Doaré, Helena Hirata, Hakiki-Talahite, et al. O sexo do trabalho. Tradução de Sueli Tomazini Cassal. Rio de Janeiro: Paz e Terra, 1986. p. 23-44.

21. Bourdieu P. A economia das trocas lingüísticas: o que falar quer dizer. São Paulo: Edusp; 1996.

22. Nolasco S. Um homem de verdade. In: Caldas $\mathrm{D}$, organizador. Homens: comportamento, sexualidade, mudanças. São Paulo: SENAC; 1997. p.13-29.

23. Giddens A. A transformação da intimidade: sexualidade, amor e erotismo nas sociedades modernas. São Paulo: Edunesp; 1993.

Enviada em: 30/03/2006

Modificada em: 10/08/2006 Aprovada em: 18/09/2006 